\title{
Ecological Reservation and Rehabilitation Measures for Urban and Rural Area With the Planning of Changshoushan Greenway as Example
}

\author{
Ziyuan Liu, Ning Wang, Zhiguang Wu \\ Urban and Rural Planning, \\ Agriculture University of Hebei, \\ Baoding, 071000, China
}

\begin{abstract}
China is in a rapid take-off stage of industrialization and urbanization. The rapid increase of industrialization level and the scale of rapid expansion of urbanization means that the demand for soil is growing. The conflict between human and the soil is getting more serious, how do we deal with the relationship between ecological protection and soil? With the Planning of Changshoushan Greenway (Shanhaiguan District, Qinhuangdao City) as an example, this article illustrates and analyzes how to rehabilitate the ecological environmental problems in a certain area by the means of "greenway design" faced by urban and rural area, to maintain the ecological protection of rural and urban structure, and to create space and environmental conditions for regional sustainable development. The implementation of greenway construction shall be in harmony with environmental protection, industrial structure, and the development of integration of spatial landscape so as to achieve the comprehensive benefits of ecology, society, and economy.
\end{abstract}

Keywords-greenway; ecological rehabilitation; ecological reservation; corridor; patches

\section{CURRENT SitUATION ANALYSIS ON URBAN AND RURAL ECOLOGY}

China's per capita resources is less than half the world average, but the unit GDP energy consumption and material consumptions is much higher than the world average, the waste water, waste emissions per unit of GDP is significantly higher than the world average, in the case of social and economic rapid development, China's ecological environment is facing greater pressure, some ecological and environmental problems will become more prominent. Since China's reform and opening up, China's rapid advance of urbanization obtained the achievements which took developed countries hundreds of years, but some local one-sided pursuit of economic growth and urban expansion excessively occupied urban and rural ecological space.

Nationwide grasssoil degradation, soil reclamation, construction occupation and other factors resulted in a decrease of 160 million grasssoil, beach and swamp with ecological conservation function decreased by $10.7 \%$, glaciers and snow cover decreased by $7.5 \%$. Saline oil and desert expanded in some areas, ecological problems become serious
The city, center of a regional political and economic operation, provides municipal and public service with many functions in the form of various buildings and ancillary facilities, especially under the current situation of China and economic development by vigorously promoting the exploitation, the scale of city land expansion spread all over the country like the sparks of fire. It is driven by interests, volume of land development rate is too large, not only at the expense of some sunlight, in the narrow floor space. It is difficult to plan landscape ecological effect rationally, city population scale also increases, and urban heat island effect is produced. These ecological problems are the same case in rural areas surrounding the city. The ecological problems in rural areas exist in two aspects, one is the village itself, and the other is the rural environmental pollution brought by the city industrial migration. Without planning, in most of the rural areas, junk cluttered, the burning of straw, livestock manure emissions randomness and other factors led to the rural poor environment, coupled with the generated outside the industrial pollution, rural areas are not exactly a piece of unspoiled land with picturesque scenery. Given the current ecological problems appeared in domestic cities and rural areas, it is urgent to relieve and cure the ecological deterioration problems.

\section{REGIONAL ECOLOGICAL CHALLENGES}

\section{A. Rehabilitation}

Ecological problem is not only an environmental issue, but a social problem. At present, the plight of ecological rehabilitation area is mainly reflected in the following two aspects: first, can not come up with a lot of land to solve the ecological land. The continuous expansion of the city, and land desertification make it harder to solve the ecological problems of land. Find a way to save the land, but also for ecological restoration is critical. Second, government financial situation does not allow, can't take out a large amount of funds to control ecological problems. It is very important to find a way which requires less financial investment and has a good effect.

\section{B. Measures}

As for different economic development level and regional characteristics around the China, the methods to solve the problem of ecological can only be done reasonably and lawfully based on different situations. In 
this project practice, on the north mountain tourism city, the application of the greenway design to repair the deterioration of the ecological problems between the urban and rural areas is pointed out. Greenway, sustainable development as a strategic planning this subject has caught the attention of many countries, the greenway in the form of a species is also very rich. Greenway has the characteristics of less investment, quick effect, conform to the requirements of the construction of low carbon city development.

The greenway planning means to prevent wild separated, protect water resources, protect heritage corridor, and provides recreational opportunities, and combined with the highway, road, river and coastline, linear green space, the implementation of greenway planning and construction, it is of great significance to enhance the ecological value of various kinds of green belt. With the development of urban and rural integration in Shanhaiguan District, the implementation of rural recreational, ecological, local culture type, industry type green road construction to promote the new rural comprehensive and coordinated development, and the ecological environment of rural and city landscape organic connection, also has an important strategic significance for the protection of ecological security pattern of urban and rural areas.

\section{The ECOlOgical ReHabilitation MeAsures --- WITH CHANGSHOUSHAN GREENWAY DESIGN AS EXAMPLE}

\section{A. The greenway of changshoushan}

Changshoushan Region is located in the northern mountainous area of Shanhaiguan District, Qinhuangdao city, Hebei Province. Ecological greenway is 8.1KM long, stretches from 102 State Road to the Changshoushan Park, along the way, there're the 102 State Road, Beijing--Shenyang Expressway, and passes through the Changshoushan scenic areas, including Yezhuyuan, Sandaoguan, and Wufo Forest Park, etc. It occupied the advantage of geographical location, economic location and traffic location, rich cultural history. Shanhaiguan greenway system will be regional greenway -- scenic greenways -- city green way -- rural greenway -community green way effectively, whose objective is: optimization of landscape pattern of mountain area, improve the quality of life of residents, and promote the development of tourism industry, to achieve the overall urban and rural, resource sharing, low carbon city, harmonious social objective.

\section{B. The planning of changshoushan greenway}

Rich in natural ecological resources and the historical and cultural characteristics, through the greenway, regional scenic areas are organically connected: Changshoushan, mountain wonderland tour area, mountain fruit leisure area, cultural experience area, modern agriculture sightseeing area, which form an ecological greenway system into multi-function, as one integrated corridor. There's basic greenway types in
Changshoushan region: self drive, biking and walking trails, regardless of the type, visitors can swim in the Changshoushan region in any area, you can see the visible water:, near far sea view; You can see the mountain: the Yanshan mountains and the natural landscape -Changshoushan, the Great Wall, Jiaoshan; You can see the forest: the original national Forest Park, and there are many jungle patches; The fields can be seen: garden and orchard, farmland, livestock breeding; visitors to watch and enjoy the beauty of nature can be of different types in different run length in the. To sum up, "To experience the beauty of ecology and enjoy a healthy life".

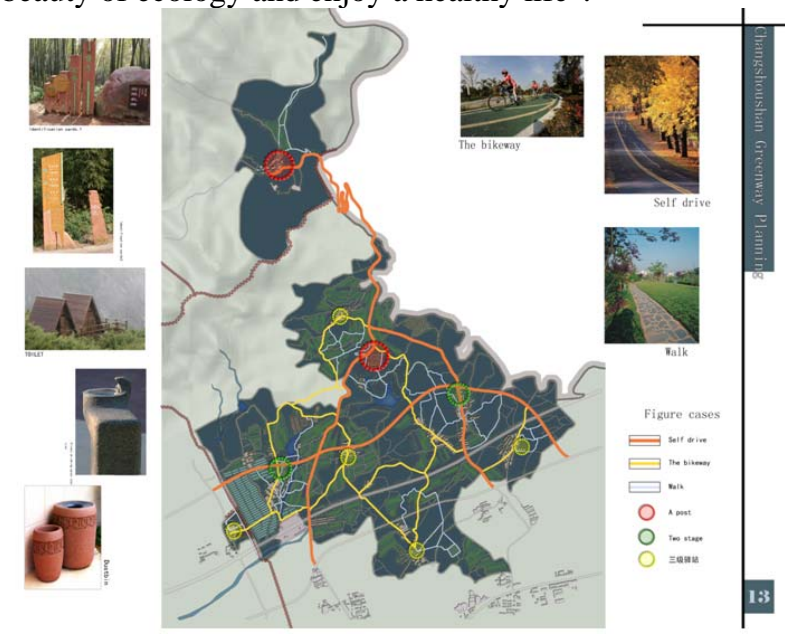

C. Ecological reservation and rehabilitation of planning and design for changshoushan

1) Cultivating ecological conservation system, protecting the environment

The greenway planning of line selection and layout of the facilities should strive to avoid the demolition, soil expropriation, combined with the existing ancient city protection area, railway and highway protection area, country lane and idle soil, abandoned soil. Make full use of the existing terrain, water, vegetation and other natural resources conditions, avoid the development of largescale, high strength, with slow traffic as priority, advocating low-carbon transport. Perfect greenway identification system and emergency rescue system are closely related to the personal safety of safety protection facilities, etc., in order to ensure the personal safety of users, maintain and improve the Shanhaiguan environmental ecological corridor and the ecological function of the coastline.

\section{2) Innovative travel patterns --- ecotourism}

Ecological tourism, as a new concept of tourism, motivates the tourists to travel with clear consciousness of ecological environment and a strong sense of self education. With the appreciation of ecological resources, taste and explore the purpose of travel, prior to take the initiative to understand astronomical geography, humanities ecology and the natural ecological knowledge of the destination; Tourists shall conform to the environmental protection standard, take an active part in 
the preservation of the natural ecological beneficial activities. At the same time, the tourists themselves shall have a high level of self-discipline that they can not destroy the environment, and improve the moral cultivation through the practice of tourism,

The concept of the Changshoushan greenway planning stems from the perspective of ecological tourism, connects each scenic spot and picking park organically through the greenway, with the company of the natural mountain, farm soil, farming, close to nature, return to nature. In the open green fields, people apply the principal of nature, learn from the nature, seek the harmonious coexistence between human and landscape and plant space, achieving a feeling of nature surrounded environment, and of a leisure tour of human in perfect harmony with Changshoushan and farm soil.

3) Strengthen the ecological sensitive area establishing mechanism

Ecological sensitive area can be understood as a decisive effect to the regional environment of large ecological elements and entities, good or bad for protection of ecological sensitive area directly affects the quality of the ecological environment, once destroyed, it is difficult to recover. Changshoushan primitive natural forest is an important ecological sensitive area, such as the national geological park, reservoirs, 4A grade scenic spot. Greenway is also the ecological sensitive area, which maintains the ecological balance of the area, influences the development of regional economy, the planning of the greenway design is to strengthen the sensitive range, as a whole, the links within the scope of the greenway, tourist facilities with green building materials, try to reduce the conflicts with nature, to protect and repair the ecological sensitive area.

4) The coordination of ecological corridor and ecological patches --- ecological sublimation

Greenway contains not only the diversity of the ecological environment, but the heritage corridor, cultural corridor, the diversity of ecological resources protection. Referenced by the ideas of greenway, the aim is to make an ecological greenway for Shanhaiguan District, integrated with nature, sports, leisure, tourism, and other functions, to comprehensively improve the quality of life of both urban and rural residents, and to strengthen the city landscape, upgrade the taste of Shanhaiguan District.

The Changshoushan greenway planning takes the greenway as corridor, patched with the mountain massif, greenway as the main line, leisure landscape resort picking park as the auxiliary line, making Shanhaiguan historical sites, waterfront, fields, woodland fishing coast connected, forming a smooth greenway, which guarantees the natural and economic benefits of the greenway and the development of scenic spots in the Green Zone in order.

5) Lead the way for urban and rural ecology --- the greenway

Changshoushan greenway is a comprehensive ecological corridor with the integration of urban and rural space, it relies on the rich natural ecological resources and historical cultural characteristics in the Shanhaiguan District, through the greenway, regional scenic areas are connected, which establishes a multi-level and multifunction, complex ecological system.

The greenway planning guidance can be summarized as "green, natural, ecological priority, industry penetration". With the urban and rural greening construction as the main mode and the principle of nature priority, in order to improve the ecological, ecological maintenance, reduce the damage to the environment, to protect the ecological environment, the urban and rural industry and environmental protection are integrated and mutually penetrated, thus finally realizes the sustainable development and highly unified economic benefits, social benefits and ecological benefits in the region.

\section{OUTLOOK}

The 21st century is an ecological century that human society will gradually step from industrial society into ecological society, in which ecological integration of urban and rural makes the hope of the future foreseeable. In the process of urban and rural planning and landscape construction, if we can establish a macro green infrastructure as quick as possible, borrow the greenway planning idea, it will make the development of urban and rural achieve twice the result with half the effort, and will play a certain positive role in alleviating the regional ecological balance, promoting economic development. Ecology is the root of environment, green space is the base of the urban and rural areas, and the construction of ecological urban and rural integration has yet a long way to go.

\section{REFERENCES}

[1] Charles Flink,Robert Searns.Greenways:A Guide To Planning Design And Development, 1993.

[2] Little C.Greenways for American.Baltimore:Johns Hopkins University Press. 1990.

[3] FabosJ G Ahern J eds.Greenways:the beginning of an international movement.Amsterdam:Elesevier.1996. 